\title{
Long non-coding RNA PAR5 inhibits the proliferation and progression of glioma through interaction with EZH2
}

\author{
XIANG-PENG WANG ${ }^{1}$, CAI SHAN $^{1}$, XING-LI DENG $^{1}$, LI-YAN LI $^{2}$ and WEI MA ${ }^{2}$ \\ ${ }^{1}$ Department of Neurosurgery, First Affiliated Hospital of Kunming Medical University, Kunming, Yunnan 650032; \\ ${ }^{2}$ Institute of Neuroscience, Kunming Medical University, Kunming, Yunnan 650050, P.R. China
}

Received March 31, 2017; Accepted September 1, 2017

DOI: 10.3892/or.2017.5986

\begin{abstract}
Emerging evidence suggests that long non-coding RNAs (lncRNAs) may be involved in modulating various aspects of tumor biology and serve as potential therapeutic targets as well as novel biomarkers in the treatment of glioma. The present study investigated the role of IncRNA, Prader Willi/ Angelman region RNA 5 (PAR5; also known as PWAR5), in glioma and its clinical significance in glioma cases. The expression levels of PAR5 were determined in clinical samples and U87, U251 cells using real-time reverse transcription quantitative polymerase chain reaction (qRT-PCR) analysis. The effects of PAR5 on cell proliferation, migration and invasion were determined using in vitro assays. RNA immunoprecipitation (RIP) and RNA pull-down assays, as well as the evauation of the expression of various oncogenes were carried out to reveal the underlying mechanisms. We found that PAR5 was significantly downregulated in glioma tissues and cell lines. Furthermore, PAR5 expression was negatively correlated with tumor size, World Health Organization (WHO) grade and Karnofsky performance score (KPS). Patients with low PAR5 expression in tumors had a worse overall survival compared to those with higher expression. Finally, in vitro restoration of PAR5 expression inhibited human glioma cell proliferation, invasion and migration by binding to EZH2 and regulating oncogene expression. This finding may provide a therapeutic approach for the future treatment of glioma.
\end{abstract}

\section{Introduction}

Gliomas, accounting for $\sim 70 \%$ of human malignant primary brain tumors, are the most lethal primary brain tumor which include a heterogenous group of tumors. It is classified by the World Health Organization (WHO) into pilocytic astrocytomas and three groups of diffusely infiltrative astrocytomas,

Correspondence to: Professor Li-Yan Li, Institute of Neuroscience, Kunming Medical University, Kunming Yunnan 650500, P.R. China E-mail: 1ly1362017@126.com

Key words: glioma, long non-coding RNAs, PAR5, PWAR5, EZH2, proliferation, motility including glioblastoma (1,2). Glioblastoma multiforme (GBM), the most common form of malignant glioma, is characterized as presenting with a highly heterogeneous composition of cells and exhibits phenotypic heterogeneity $(1,3)$. Although a series of treatment protocol have been developed and several potential drug targets have been discovered, the survival rate of GBM patients has not been significantly increased $(4,5)$. Thus, it is still necessary to identify novel and effective biomarkers which may help the development of therapeutic targeted drugs.

Long non-coding RNAs (lncRNAs), which were initially argued to be spurious transcriptional noise, are now recognized as a class of RNAs with transcripts longer than 200 nucleotides without the function of encoding proteins (5-7). Recent studies have found that lncRNAs: i) regulate downstream target genes by multiple means via cis- and trans-regulatory effects $(8,9)$; and ii) play a critical regulatory role in many human diseases, including cancer $(10,11)$. Other investogators have reported that a growing number of lncRNAs can cooperate with neighbor genes to form 'IncRNA-mRNA' pairs to affect their function (12-15). Close relationships are often found between these lncRNAs and their near-by mRNAs in expression or function. Based on microarray-based data, Zhang et al previously demonstrated that specific lncRNA expression patterns are associated with different histological subtypes and malignant behaviors in glioma (16). Furthermore, certain lncRNAs were found to be of prognostic significance, suggesting that lncRNAs may have important roles in gliomagenesis and may serve as novel therapeutic targets and biomarkers (17). Previously, downregulation of IncRNA Prader Willi/Angelman region RNA 5 (PAR5; also known as PWAR5, Homo sapiens, gene ID, 8123) was demonstrated to be associated with GBM (17), yet the functions of PAR5 have not been well investigated in this type of tumor.

Histone modifications and global aberrations at the histone level may result in distorted patterns of gene expression, and malfunction of proteins that regulate chromatin modification and remodeling $(18,19)$. Reports have shown that histone modifications play important roles in the pathogenesis of diffuse gliomas in adults and children (20). Typical lncRNAs can coordinate histone modifications by binding to various histone modification enzymes. It is well known that polycomb repressive complex 2 (PRC2) is a methyltransferase for histone $\mathrm{H} 3$ lysine 27 trimethylation (H3K27me3), consisting of enhancer 
of zeste homolog 2 (EZH2), suppressor of zeste 12 (SUZ12) and embryonic ectoderm development (EED) (20). Lysinespecific demethylase 1 (LSD1) is a demethylase that mediates the enzymatic demethylation of histone $\mathrm{H} 3$ lysine 27 dimethylation (H3K4me2) (21). It was revealed that the 5 ' domain of IncRNA HOTAIR binds to PRC2, whereas the 3 ' domain binds to the LSD1/CoREST/REST complex, which acts as a modular scaffold (22).

Previous studies have also shown that lncRNAs influence the expression of downstream targets via recruiting PRC2 or LSD1 proteins $(23,24)$. Therefore, the present study aimed to explore the possible effects of PAR5 involved in the oncogenic events of glioma and the interaction between PAR5 and PRC2 or LSD1 in glioma cells.

\section{Materials and methods}

Ethical approval. The present study protocol complied with the Declaration of Helsinki and was approved by the Medical Ethics Committee of Kunming Medical University. Glioma tumor specimens were obtained from consenting patients at the Hospital of Yunnan Province (Kunming, China).

Tissues preparation, molecular assay and cell culture. Eighty-seven patients, attending (February 2013 to December 2014) the clinic of the First Affiliated Hospital of Kunming Medical University, provided consent to participate in the present study. All of patients accepted to undergo surgery at our hospital for the first time, without any antitumor treatment. The specimens were histopathologically verified as primary glioma by three independent senior pathologists according to the WHO Classification of Tumors of the Central Nervous System (CNS) $(25,26)$. Subsequently, the primary carcinoma tissues and the matched adjacent normal tissues (at least $3 \mathrm{~cm}$ away from the tumor) (27) were collected for analysis. The demographic and clinic characteristics of the unselected 87 glioma population are summarized in Table I.

DNA extraction from frozen tumor tissue was performed using a DNeasy Blood and Tissue kit (Qiagen, Tokyo, Japan). The presence of hotspot mutations in isocitrate dehydrogenase (IDH) gene 1 (R132)/2 (R172), as well as the two mutation hotspots in the TERT promoter (C228T and C250T), were assessed mainly by pyrosequencing and partly by Sanger sequencing, as previously reported $(28,29)$. The methylation status of the MGMT promoter was also analyzed using a customized pyrosequencing assay, essentially as previously described (30). A SALSA MLPA kit probemix (P088-C1; MRC-Holland, Amsterdam, The Netherlands) was employed for analysis of the copy number of $1 \mathrm{p} / 19 \mathrm{q}$ as previously described (31).

Human normal skin fibroblast HF cell line and glioma cell lines U87 and U251 were purchased from the Cell Bank of the Chinese Academy of Sciences (Shanghai, China). The cells were cultured in Dulbecco's modified Eagle's medium (DMEM) (Gibco, Grand Island, NY, USA) supplemented with $10 \%$ fetal bovine serum, $100 \mathrm{U} / \mathrm{ml}$ penicillin and $100 \mu \mathrm{g} / \mathrm{ml}$ streptomycin (BioWest, Nuaillé, France), at $37^{\circ} \mathrm{C}$ in a humidified atmosphere containing $5 \% \mathrm{CO}_{2}$. All of the cells are negative for HIV-1, HBV, HCV, mycoplasma, bacteria, yeast and fungi before experiment.
Table I. Summary of the patient cohort with glioma in the present study.

\begin{tabular}{lc}
\hline Parameters & No. of cases $(\%)$ \\
\hline Total glioma cases & $87(100)$ \\
Age ( $\geq 50$ years) & $41(47.1)$ \\
Sex & \\
Male & $44(50.6)$ \\
Female & $43(49.4)$ \\
Location of tumor & \\
Frontal & $35(40.2)$ \\
Occipital & $12(13.8)$ \\
Temporal & $14(16.1)$ \\
Others & $26(29.9)$ \\
WHO grade & \\
I & $16(18.4)$ \\
II & $18(20.7)$ \\
III & $25(28.7)$ \\
IV & $28(32.2)$ \\
$I D H 1$ mut & $45(51.7)$ \\
$M G M T$ methy & $51(58.6)$ \\
Ip/19q codel & $52(59.8)$ \\
$T E R T$ mut & $28(32.2)$ \\
\hline
\end{tabular}

mut, mutation; methy, methylation; codel, codeletion; WHO, World Health Organization.

Cell transfection. RNA oligoribonucleotides targeting to PAR5 were prepared for cell transfection. The small interfering RNAs (siRNAs) that specifically target human PAR5 mRNA (si-PAR5) were designated and purchased from RiboBio (Guangzhou, China). According to the manufacturer's protocol, a final concentration of $2 \times 10^{5} \mathrm{U} 87$ and U251 cells were seeded into each well of a 6 -well plate and transfected for $48 \mathrm{~h}$ using Lipofectamine 2000 reagent (Invitrogen, Carlsbad, CA, USA). The negative control duplex containing siRNA (si-NC; RiboBio), not homologous to any human genome sequences, was employed as control. At the end of transfection, U87 and U251 cells were collected for further analyses.

Full-length PAR5 cDNA was synthesized by Biomarker Technologies (Beijing, China) and ligated into the pcDNA3.1(+) vector (Invitrogen). PcDNA3.1-PAR5 (p-PAR5) and empty vector ( $\mathrm{p}-\mathrm{NC}$ ) were transfected into glioma cells, U87 and U251, cultured in 6-well plates using the Lipofectamine 2000 reagent (Invitrogen). Cells were harvested for qRT-PCR analysis $48 \mathrm{~h}$ after transfection.

Quantitative real-time PCR ( $q R T$-PCR). The expression of PAR5 in the human glioma cells and specimens from glioma patients was determined by qRT-PCR as previously described (32). Total RNA was isolated using TRIzol according to manufacturer's instructions. qRT-PCR was performed using the iQ SYBR-Green SuperMix (Bio-Rad, Hercules, CA, USA) as per the protocol of the manufacturer. GAPDH served as an endogenous control. IncRNA expression levels were normalized by calculating the IncRNAs/GAPDH expression ratio 
$\left(2^{-\Delta \mathrm{Ct}}\right)$. Amplification of qRT-PCR was performed at $95^{\circ} \mathrm{C}$ for $3 \mathrm{~min}$, followed by 40 cycles at $95^{\circ} \mathrm{C}$ for $15 \mathrm{sec}$ and $60^{\circ} \mathrm{C}$ for $60 \mathrm{sec}$. The primer sequences were as follows: GAPDH sense, 5'-CGAGATCCCTCCAAAATCAA-3' and antisense, 5'-TTC ACACCCATGACGAACAT-3'; PAR5 sense, 5'-TGATGTGG GTGTTGATAC-3' and antisense, 5'-ACTCAAAGGCAAGA ACTA-3' (32).

Cell viability assay. Following various treatments, cell viability was determined using the tetrazolium salt 3-(4,5-dimethylthiazol-2-yl)-2,5-diphenyltetrazolium bromide (MTT) assay. Briefly, $1 \times 10^{5}$ cells $/ \mathrm{ml}$ cells were plated into 96 -well culture plates in $200 \mu \mathrm{l}$ of culture medium/well. After $48 \mathrm{~h}$ of culture with treatment, $20 \mu \mathrm{l}$ of $5 \mathrm{mg} / \mathrm{ml}$ MTT was added to each well and incubated at $37^{\circ} \mathrm{C}$ for $4 \mathrm{~h}$. The medium was then gently aspirated and $150 \mu \mathrm{l}$ of dimethyl sulfoxide (DMSO) was added to each well to solubilize the formazan crystals. The absorbance of each sample was immediately measured using a microplate reader (Multiskan MK3; Thermo Fisher Scientific, Inc., Waltham, MA, USA) at $570 \mathrm{~nm}$.

Migration and invasion assays. Transwell (Millipore, Billerica, MA, USA) and Matrigel (BD Biosciences, Franklin Lakes, NJ, USA) chamber plates were employed to evaluate the motility and invasiveness as previously described (33). After $24 \mathrm{~h}$ of incubation, cells remaining in the upper chamber or on the upper membrane were carefully removed. Cells adhering to the lower membrane were stained, imaged and counted using an IBX3 inverted microscope (Olympus, Tokyo, Japan) (34). The experiments were repeated three times.

Scratch wound assay. Scratch wound assay was employed to detect the migration of the glioma cell lines treated with various treatments, as previously described (35). Briefly, at $\sim 80 \%$ confluency, the glioma cells transfected with various chemicals were seeded onto 6 -well plates and incubated at $37^{\circ} \mathrm{C}$, respectively. Then, using a $10-\mu 1$ pipette tip, a vertical scratch wound was made through the center of each well plate. The cells were then washed three times with phosphate-buffered saline (PBS) to remove the scratched cells, and fresh serum-free medium was transferred. After $48 \mathrm{~h}$, the cells were examined by light microscopy (Olympus) at a magnification of $\mathrm{x} 200$ to determine the resealing of the cell monolayer.

RNA immunoprecipitation (RIP) assay. RIP was performed using the EZ-Magna RIP kit (Millipore) according to the manufacturer's protocol. Briefly, at $80-90 \%$ confluency, U87 and U251 cells were scraped off the culture plate and lysed in RIP lysis buffer. A total of $100 \mu \mathrm{l}$ of whole cell extract was incubated with RIP buffer containing magnetic beads conjugated with antibodies against EZH2, LSD1, SUZ12 or control $\operatorname{IgG}$ (Millipore) for $8 \mathrm{~h}$ at $4^{\circ} \mathrm{C}$. The beads were treated with wash buffer, then the complexes were incubated with $0.1 \%$ $\mathrm{SDS} / 0.5 \mathrm{mg} / \mathrm{ml}$ proteinase $\mathrm{K}$ for $30 \mathrm{~min}$ at $55^{\circ} \mathrm{C}$ to remove proteins. Finally, immunoprecipitated RNA was purified and analyzed by qRT-PCR.

RNA pull-down assays. The pCDNA3.1-PAR5 vector was cleaved by restriction enzyme NruI and treated with RNase-free DNase I (Takara, Dalian, China). PAR5 was transcribed from this vector using the mMESSAGE mMACHINE $\mathrm{T}^{\circledR}$ kit (Ambion, Carlsbad, CA, USA) and purified using the RNeasy Mini kit (Qiagen, Valencia, CA, USA) in vitro. The Pierce RNA 3'-End Desthiobiotinylation kit (Thermo Fisher Scientific, Inc.) was employed to label the 3 ' end of PAR5, according to the instructions. The extensively expressed messenger RNA (mRNA) stabilizing protein HuR (encoded by ELAVL1) was employed and served as the positive control for RNA pulldown assays. The nonspecific IgG antibody was used as a negative control. One milligram of protein from the U87 cell extracts was then mixed with 45 pmol of biotinylated RNA, and incubated with $50 \mu \mathrm{l}$ of magnetic beads for $1 \mathrm{~h}$ at $4^{\circ} \mathrm{C}$ (Thermo Fisher Scientific, Inc.). The RNA-protein complex was isolated from magnetic beads using Biotin Elution Buffer and boiled in SDS buffer for $5 \mathrm{~min}$. The retrieved protein was detected using standard western blotting techniques.

Western blotting. Using cell lysis buffer for western blotting (Beyotime Biotechnology, Shanghai, China), total proteins were isolated from the cells with various treatments. Subsequently, the protein concentrations were detected using the BCA assay kit (Beyotime Biotechnology) according to the manufacturer's protocol. The protein expression of EZH2, epidermal growth factor receptor (EGFR), VEGF-A, cyclin A, AKT and p-AKT (ser473) was detected as previously described (14). Briefly, protein samples were separated by $10 \%$ SDS-PAGE and transferred onto nitrocellulose membranes (Beyotime Biotechnology). The membranes were blocked with $5 \%$ non-fat milk for $2 \mathrm{~h}$, and then incubated overnight at $4^{\circ} \mathrm{C}$ with the primary antibody, including EZH2 (1:1,000; Millipore), EGFR (1:1,000), VEGF-A $(1: 1,000)$, cyclin A (1:500), AKT (1:500) and phosphorylatedAKT (p-AKT) (ser473; 1:1,000) (all from Cell Signaling Technology, Danvers, MA, USA). Signals were detected using the enhanced chemiluminescence (ECL) luminol reagent (Millipore).

Statistical analysis. Data are presented as means \pm standard deviation (SD). SPSS version 21.0 software (SPSS, Inc., Chicago, IL, USA) was employed for analyses. Multivariate logistic regression analysis was performed to evaluate the association between PAR5 expression levels (low or high level) and clinicopathological/genetic characteristics of the glioma patients. The strength of association was measured using odds ratios (ORs) with $95 \%$ confidence interval (CI). Logistic regression was used for ordinal data to estimate adjusted ORs. The statistical significance of PAR5, EGFR, VEGF-A, cyclin A, AKT and p-AKT (ser473) expression, MTT cell activity, migration and invasion among groups following different treatments were determined using one-way ANOVA. Significance level was predetermined to be $p \leq 0.05$ unless otherwise indicated.

\section{Results}

Abnormal expression of PAR5 in glioma patients and cells. The levels of PAR5 were examined in the tumor tissues of glioma patients by qRT-PCR analysis. The PAR5 expression was significantly decreased in the glioma tissue compared with that noted in the adjacent normal brain tissues ( $\mathrm{p}<0.05$; Fig. 1A). 

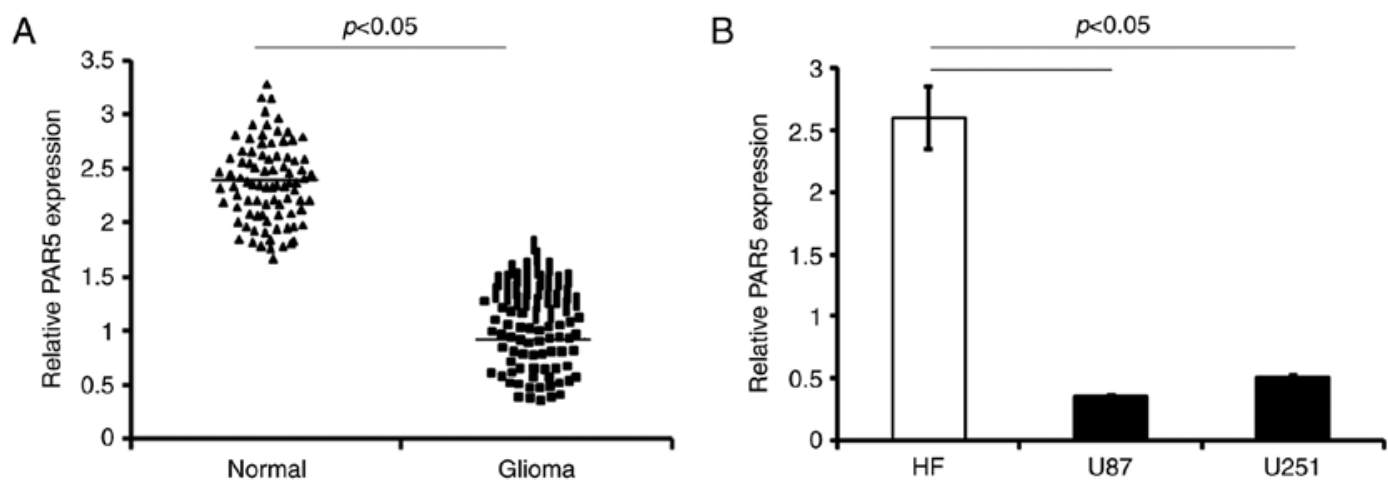

Figure 1. PAR5 expression is decreased in glioma tissues and cell lines. (A) Relative expression of PAR5 in normal adjacent tissues and glioma tumor tissues was examined by qRT-PCR ( $\mathrm{n}=87$ ). (B) Relative expression of PAR5 in normal human HF and glioma cell lines, U87 and U251. Data are represented as means \pm SD. Five independent experiments were performed in triplicate $(n=5)$.

A

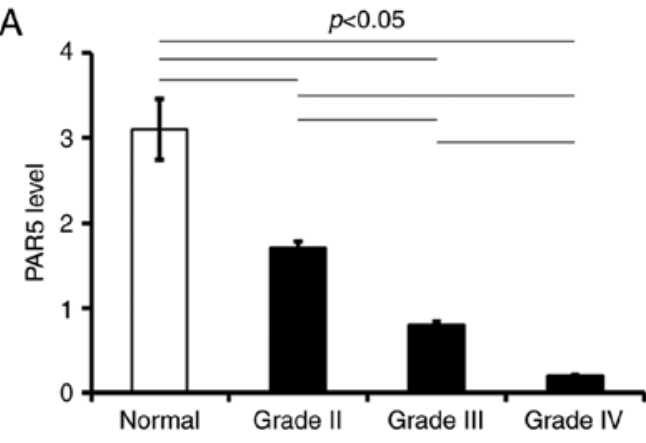

B

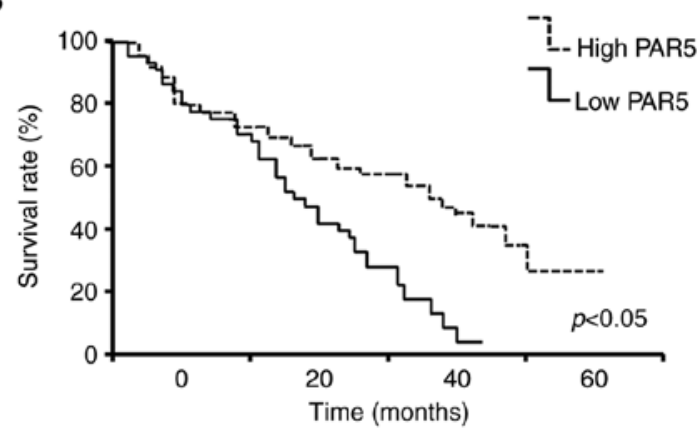

Figure 2. Low PAR5 expression is associated with increasing grade of glioma. (A) Relative expression of PAR5 in normal adjacent tissues and glioma patient tissues according to WHO grade, II-IV. (B) Five-year overall survival rates of glioma patients according to the PAR5 expression level by Kaplan-Meier survival analysis.

Consistently, the PAR5 level was lower in both human glioma cell lines, U87 and U251 (U87 vs. HF cells, and U251 vs. HF cells respectively, $\mathrm{p}<0.05$; Fig. 1B).

PAR5 expression is associated with glioma progression. The expression of PAR5 in GBM tumors collected from patients was determined by qRT-PCR. According to the PAR5 level, the enrolled patients were divided into two cohorts: those with less than or equal to the median expression level of PAR5 (low level) and those with more than the median expression level of PAR5 (high level). The clinicopathologic association of PAR5 mRNA levels in the glioma tumors were analyzed. The level of PAR5 expression in glioma tissues was lower when compared to that in the adjacent normal brain tissues, and decreased with increasing WHO grade ( $\mathrm{p}<0.05$; Fig. $2 \mathrm{~A}$ ). Kaplan-Meier survival analysis showed that patients with high PAR5 expression had significantly increased overall survival compared with patients with low PAR5 expression $(\mathrm{p}<0.05$; Fig. 2B).

Analysis showed that low PAR5 expression was significantly correlated with tumor size $(\geq 5 \mathrm{~cm}, \mathrm{r}=0.469, \mathrm{p}=0.0019,<0.05)$, WHO grade $(\mathrm{r}=0.376, \mathrm{p}=0.0035,<0.05)$ and Karnofsky performance score $(\mathrm{KPS})$ score $(\mathrm{r}=0.297, \mathrm{p}=0.005,<0.05)$ (Table II). Notably, there were 25 patients with low PAR5 expression classified as having highly malignant grade IV glioblastomas (GBMs). Age at diagnosis, sex and resection status were not correlated with PAR5 expression (Table II).
Assessment of the molecular features of the unselected glioma patients revealed that PAR5 expression was significantly associated with $I D H 1$ mutation $(\mathrm{r}=0.809$, $\mathrm{p}=0.000,<0.05), M G M T$ methylated status $(\mathrm{r}=0.201$, $\mathrm{p}=0.013,<0.05)$ and TERT promoter mutation $(\mathrm{r}=0.721$, $\mathrm{p}=0.000,<0.05)($ Table III).

Evaluation of the effectiveness of PAR5 SiRNA and overexpression plasmid transfection. The glioma cell lines, U87 and U251, as well as the HF cells were stably transfected with si-PAR5, p-PAR5 or the matched control si-NC, p-NC. The data showed that stable expression of PAR5 siRNA (si-PAR5) in U87, U251 and HF cells resulted in $>70 \%$ decrease in PAR5 RNA (Fig. 3A). In the p-PAR5-transfected glioma cells, the PAR5 levels as detected were significantly higher than levels in the matched p-NC controls, respectively ( $<<0.05$; Fig. 3B). The PAR5 level was upregulated at least 1.7-fold in the HF cells, while the level was increased significantly in the glioma cells (4.7-fold in U87 cells; 4.2-fold in U251 cells), compared with the matched p-NC cell lines, respectively.

PAR5 inhibits proliferation, migration and invasion of glioma cells. Transfection with p-PAR5 significantly decreased cell viability, and suppressed migration and invasion in both U87 and U251 cell lines, compared with these parameters in the matched p-NC treated cell lines, respectively. Functional inhibition of endogenous PAR5 by special si-PAR5 induced a 
A

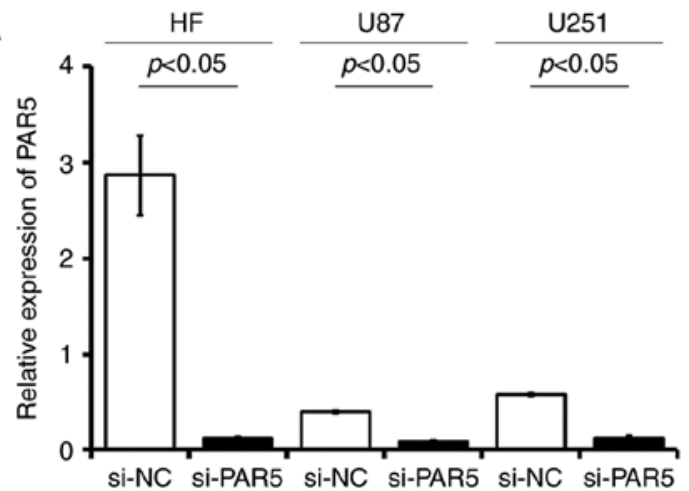

B

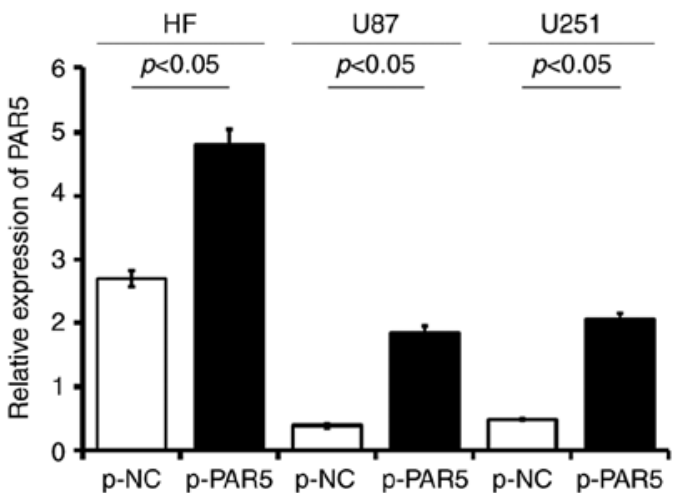

Figure 3. Relative PAR5 expression after siRNA and plasmid transduction. (A) PAR5 levels were detected by qRT-PCR in HF, U87 and U251 cells following PAR5 siRNA transfection. (B) PAR5 levels were detected by qRT-PCR in HF, U87 and U251 cells following PAR5 overexpression plasmid transfection. si-NC, PAR5 siRNA negative control; si-PAR5, PAR5 siRNA. p-NC, blank plasmid serving as control; p-PAR5, pcDNA3.1-PAR5. Data are represented as means \pm SD. All data are representative of five independent experiments $(n=5)$.

Table II. PAR5 level is associated with clinicopathological features of the glioma cases.

\begin{tabular}{|c|c|c|c|c|}
\hline & \multicolumn{2}{|c|}{ PAR5 levels $(n=87)$} & \multirow[b]{2}{*}{$\mathrm{r}_{\mathrm{s}}$} & \multirow[b]{2}{*}{ P-value } \\
\hline & $\begin{array}{c}\text { Low level } \\
n=47\end{array}$ & $\begin{array}{c}\text { High level } \\
n=40\end{array}$ & & \\
\hline Ages (years) & & & 0.005 & 0.65 \\
\hline$<50$ & 22 & 24 & & \\
\hline$\geq 50$ & 25 & 16 & & \\
\hline Sex & & & 0.069 & 0.32 \\
\hline Male & 25 & 19 & & \\
\hline Female & 22 & 21 & & \\
\hline Resection status & & & 0.128 & 0.19 \\
\hline Total & 23 & 22 & & \\
\hline Subtotal & 24 & 18 & & \\
\hline Tumor size $(\mathrm{cm})$ & & & 0.469 & 0.0019 \\
\hline$<5$ & 19 & 31 & & \\
\hline$\geq 5$ & 28 & 9 & & \\
\hline Location of tumor & & & 0.024 & 0.59 \\
\hline Frontal & 20 & 15 & & \\
\hline Occipital & 7 & 5 & & \\
\hline Temporal & 8 & 6 & & \\
\hline Others & 12 & 14 & & \\
\hline $\begin{array}{l}\text { Histopathological } \\
\text { diagnosis (WHO) }\end{array}$ & & & 0.376 & 0.0035 \\
\hline Grade I & 2 & 14 & & \\
\hline Astrocytoma II & 6 & 12 & & \\
\hline Astrocytoma III & 11 & 9 & & \\
\hline $\begin{array}{l}\text { Oligodendro- } \\
\text { gliomas II/III }\end{array}$ & 3 & 2 & & \\
\hline IV, glioblastomas & 25 & 3 & & \\
\hline KPS score & & & 0.297 & 0.005 \\
\hline$<80$ & 33 & 8 & & \\
\hline$\geq 80$ & 14 & 32 & & \\
\hline
\end{tabular}

PAR5, Prader Willi/Angelman region RNA 5; WHO, World Health Organization; KPS, Karnofsky performance score. P-value in bold print indicates a significant difference.
Table III. Correlation between PAR5 level and molecular features of the glioma cases.

\begin{tabular}{llccc}
\hline & \multicolumn{2}{c}{ PAR5 (n=87) } & & \\
\cline { 2 - 3 } & $\begin{array}{l}\text { Low level } \\
\mathrm{n}=47(\%)\end{array}$ & $\begin{array}{c}\text { High level } \\
\mathrm{n}=40(\%)\end{array}$ & $\mathrm{r}_{\mathrm{s}}$ & P-value \\
\hline IDH1/2 status & & & 0.809 & $\mathbf{0 . 0 0 0}$ \\
WT & $37(78.7)$ & $5(12.5)$ & & \\
mut & $10(21.3)$ & $35(87.5)$ & & \\
MGMT status & & & 0.201 & $\mathbf{0 . 0 1 3}$ \\
Methylation & $30(63.8)$ & $6(15)$ & & \\
Unmethylation & $17(36.2)$ & $34(85)$ & & \\
1p/19q status & & & 0.137 & 0.087 \\
Non-codel & $20(42.6)$ & $17(42.5)$ & & \\
Codel & $27(57.4)$ & $23(57.5)$ & & \\
TERT status & & & 0.721 & $\mathbf{0 . 0 0 0}$ \\
WT & $15(31.9)$ & $27(67.5)$ & & \\
mut & $32(68.1)$ & $13(32.5)$ & & \\
\hline
\end{tabular}

WT, wild-type; mut, mutation; 1p/19q code, co-deletions of chromosome $1 p / 19 q$; TERT, telomerase reverse transcriptase. P-value in bold print indicates a significant difference.

significant promotion in viability in the U87 (Fig. 4A; $p<0.05$ ) and U251 cell lines (Fig. 4B; $\mathrm{p}<0.05$ ).

Restoration of the PAR5 level in glioma cells by transfection with p-PAR5 significantly reduced cellular motility compared with that noted in the p-NC-treated groups. The migration assay revealed that the number of crystal violet-stained cells was significantly decreased in the p-PAR5treated cells, compared with that in the matched p-NC control groups ( $\mathrm{p}<0.05$; Fig. $4 \mathrm{C}$ and D). p-PAR5 transfection decreased the number of U87 and U251 cells that migrated through the Transwell membrane by at least $80 \%$ compared with the p-NC-treated cells. Scratch wound assay showed that transfection with p-PAR5 significantly impaired the invasiveness of U87 (Fig. 4E and G) and U251 (Fig. 4F and H) cells, in comparison with that of the control p-NC-treated cells, 
A

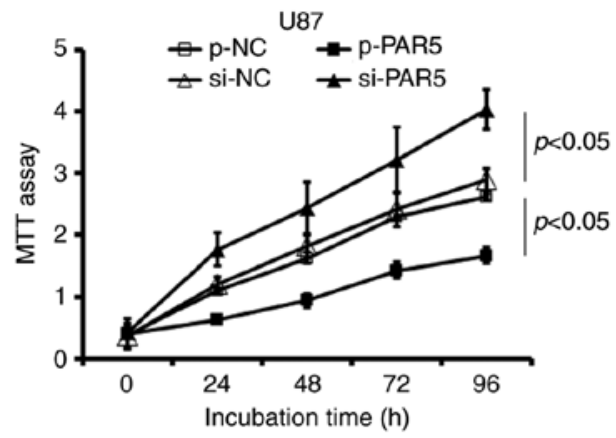

C

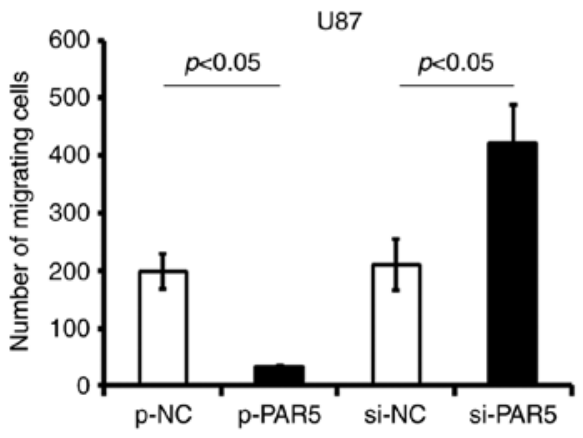

E

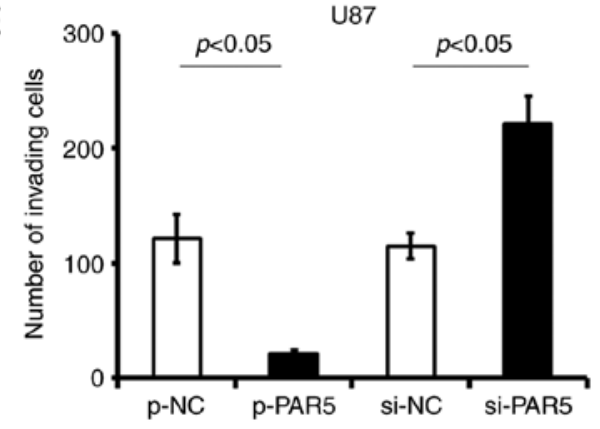

G

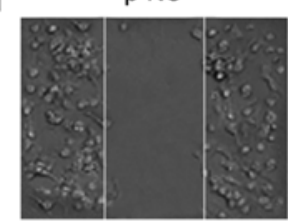

$\mathrm{H}$

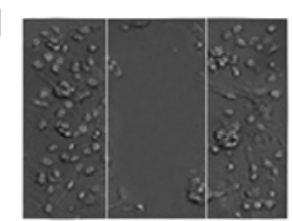

B
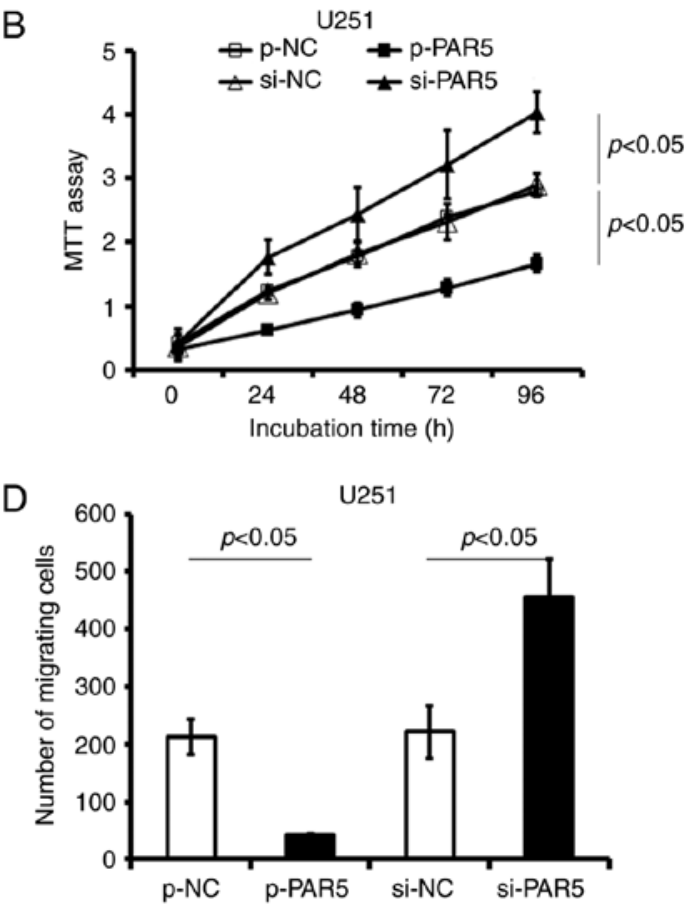

$\mathrm{F}$

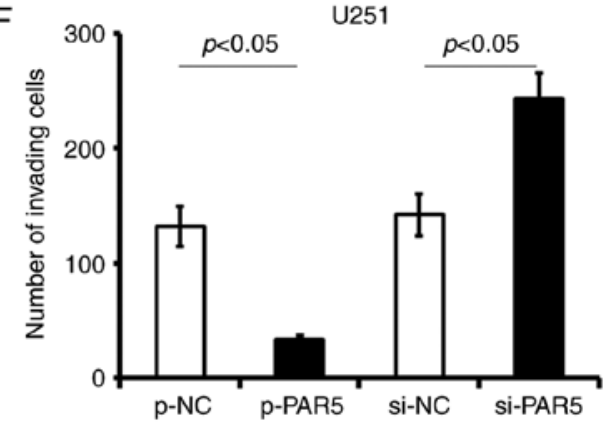

si-NC
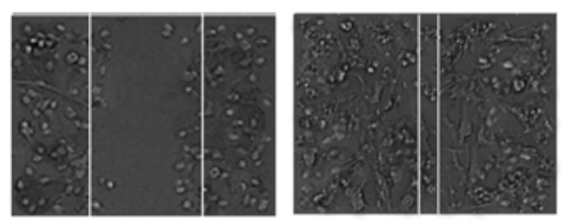

U87
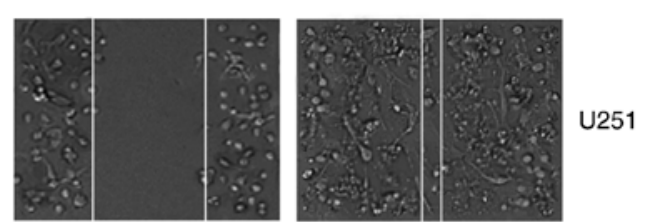

Figure 4. PAR5 inhibits the proliferation, migration and invasion of glioma cells. (A and B) Cell proliferation was evaluated by MTT assay after cell transfection; p $<0.05$ vs. the matched negative controls. Quantitative analysis of the migratory and invading cells in (C and E) U87 and (D and F) U251 cells after transfection. Scratch wound assay was also performed to evaluate the motility of glioma (G) U87 and (H) U251 cells. Light microscopy images are shown immediately after scratching of the monolayer and $48 \mathrm{~h}$ later. Data are represented as means \pm SD. All data are representative of five independent experiments $(n=5)$. si-NC, PAR5 siRNA negative control; si-PAR5, PAR5 siRNA. p-NC, blank plasmid served as control; p-PAR5, pcDNA3.1-PAR5.

respectively $(\mathrm{p}<0.05)$. In contrast, si-PAR5 transfection significantly promoted the migration and invasion in both glioma cell lines (vs. the matched si-NC control, $\mathrm{p}<0.05$, respectively; Fig. 4).

PAR5 interacts directly with EZH2 in glioma cells. The binding of PAR5 with EZH2 was confirmed by RIP and qRT-PCR in
U87 and U251 cells. RIP assays and subsequent qRT-PCR revealed that PAR5 was abundant in the RIP samples using LSD1, EZH2 and SUZ12 antibodies as compared with the samples using nonspecific antibodies IgG, which confirmed the specificity of RIP assays and qRT-PCR performed in the present study (Fig. 5A). The relative expression of PAR5 was significantly enriched in the EZH2 antibody-treated glioma 


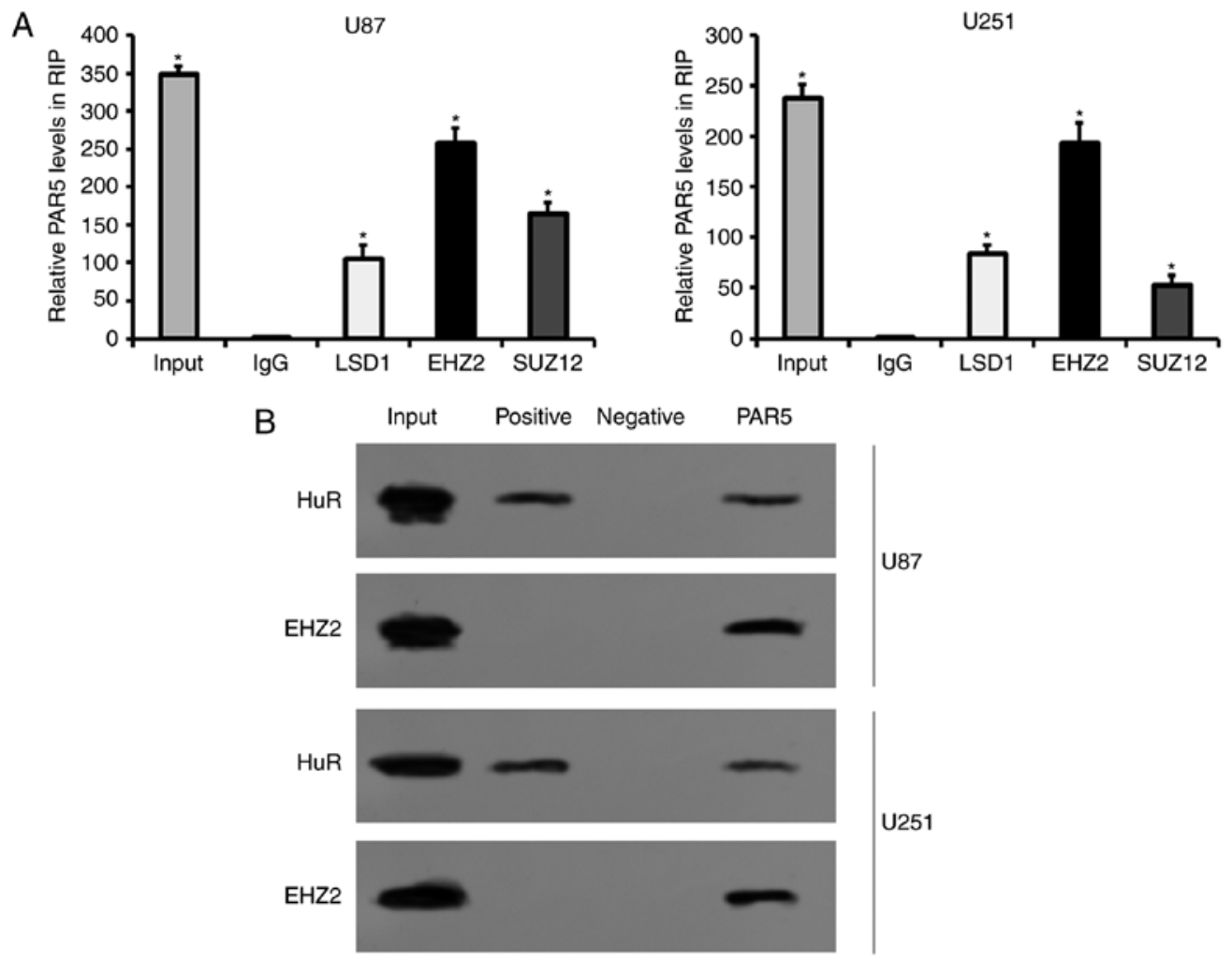

Figure 5. PAR5 interacts with EZH2 in glioma cells. (A) RIP experiments were performed using the EZH2, LSD1, SUZ12 antibodies in U87 and U251 cells and the co-precipitated RNA was subjected to qRT-PCR for PAR5. Expression levels of PAR5 RNA are expressed as fold enrichment in EZH2 RIP relative to the matched IgG control. (B) RNA pull-down and western blot assays of the specific association of PRC2 core proteins with PAR5 revealed that biotinylated PAR5 could bind to EZH2. HuR served as the positive control and IgG was used as a negative control, indicating the sensitivity and specificity of RNA pull-down performed in the present study. Data are shown as the mean \pm SD of three independent experiments; ${ }^{*} \mathrm{p}<0.05$

U87 and U251 cells, compared with that in the LSD1 and SUZ12 antibody-treated ones, respectively (Fig. 5A). The results showed that PAR5 bound directly to EZH2 in both U87 and U251 cells. The following RNA pull-down assays and western blotting also confirmed the interaction between PAR5 and EZH2 (Fig. 5B). Additionally, HuR served as the positive control, indicating the sensitivity of RNA pull-down performed in the present study (Fig. 5B). These data suggest that EZH2 specifically binds to PAR5 in U87 and U251 cells.

PAR5 inhibits expression of oncogenes in glioma cells. Given the significant inhibition of cell growth and motility by PAR5 in the glioma cells, the involvements of several genes related with proliferation, cell cycle and tube formation of tumor cells were investigated. The data showed that PAR5 reduced the expression of EGFR, VEGF-A and cyclin A (Fig. 6). Additionally, the expression of p-AKT was decreased by PAR5 overexpressed plasmid transfection (Fig. 6).

\section{Discussion}

In the present study, we found that: i) significantly downregulated PAR5 was negatively correlated with clinicopathological and genetic features; ii) a cohort with PAR5 low expression in tumors had a worse overall survival rate compared to those with PAR5 high expression; iii) PAR5 inhibited human glioma cell proliferation, invasion and migration; iv) PAR5 interacted with EZH2 and suppressed expression of various oncogenes including EFGR, VEGF-A, cyclin A and p-AKT in glioma cells.

PAR5 was previously reported to be: i) significantly downregulated predominantly in one specific hepatitis $\mathrm{C}$ virusrelated hepatocellular carcinoma (HCC) type (32); ii) correlated with poor prognostic outcomes in human glioblastoma multiforme (17). However, there is limited information concerning PAR5. Recently, the functions of PAR5 have not been well investigated. Thus, additional studies may be needed to elucidate the mechanistic connection between PAR5 and the molecular pathogenesis of tumors, particularly glioma. We found that endogenous PAR5 expression was significantly decreased in glioma tissues and cell lines, while a low level of PAR5 was associated with pathological features and the survival rate of glioma patients. Low PAR5 expression was correlated with tumor size ( $\geq 5 \mathrm{~cm}$ ), WHO grade (III-IV) and KPS score $(<80)$, which indicated the deterioration of glioma patients. Evaluation of the molecular genetic features of this unselected glioma cohort revealed that PAR5 expression was also associated with IDH1/2 mutation, MGMT methylated status and TERT promoter mutation.

The presence of the $I D H 1 / 2$ mutation in astrocytoma patients was found to have a positive effect on overall survival $(36,37)$. They are rare in primary GBM and absent in pilocytic astrocytomas and are often associated with $M G M T$ promoter hypermethylation ('MGMT methylation'), a well-established prognostic marker for primary GBM and a predictive marker for the response to temozolomide in elderly 
A

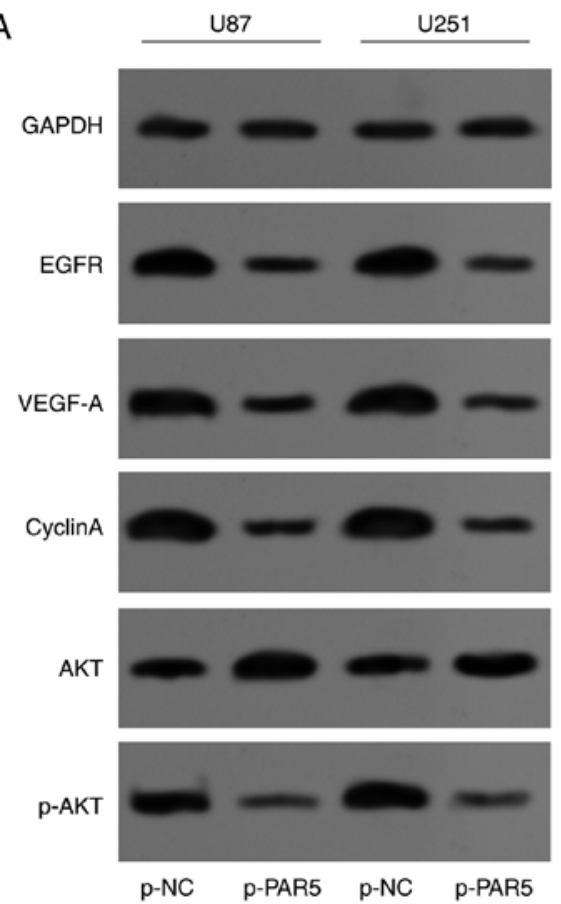

B
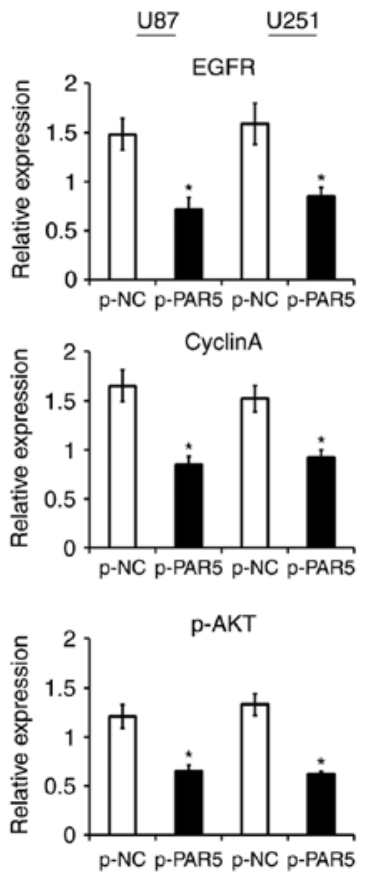
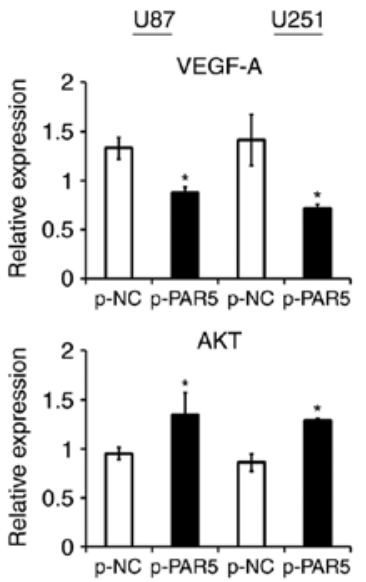

Figure 6. PAR5 restoration alters expression of various oncogenes in glioma cells. (A) Representative bands of various proteins in glioma cells after PAR5 expression restoration, as detected by western blotting. (B) Quantitative analysis of the expression levels of EGFR, VEGF-A, cyclin A, AKT and p-AKT proteins. GAPDH served as a control. Data are shown as the mean \pm SD of three independent experiments. ${ }^{*}$ p $<0.05$ vs. p-NC. p-NC, blank plasmid serving as control; p-PAR5, pcDNA3.1-PAR5.

GBM patients (38-40). In the present study, presence of the IDHI/2 mutation was associated with significantly enhanced overall survival in glioma patients with a high PAR5 level, while the presence of IDH-wild-type in patients with a low level of PAR5 suffered from poor overall survival. In the present unselected cohort, the presence of MGMT methylation was frequently detected in those with low PAR5 expression (63.8\%), in which more patients were diagnosed with glioblastomas (GBMs) (25 vs. 3 cases). PAR5 expression was highly consistent with $I D H 1 / 2$ mutation and MGMT methylation. Our data also revealed that the TERE promoter mutations and $I D H$-wild-type are the common genotypes observed in the cohort with a PAR5 low expression level, which tend to be associated with poor prognosis. Research has demonstrated that TERT promoter mutations almost always coincide with $I D H$ mutations and $1 \mathrm{p} / 19 \mathrm{q}$ codeletion in oligodendrogliomas, whereas a combination of TERT mutation and IDH-wild-type is the most common genotype observed in GBM (41). Given these findings, the combination of PAR5 expression, $I D H$ and TERT mutations may be useful to define glioma subclasses and predict outcome in GBM. Assessment of expression of PAR5 in glioma patients may be valuable for application as a molecular classification of $I D H$-wild-type gliomas and a prognostic indicator of GBM. However, further investigation between PAR5 and the well-established molecular markers is necessary.

Moreover, restoration of PAR5 expression using a PAR5overexpressing plasmid resulted in retardation of proliferation, decreased invasion and migration in the human glioma cells, U87 and U251. Reversely, si-RNA targeting PAR5 promoted proliferation and increased motility in the glioma cells. These results suggest that PAR5 may act as a tumor suppressor in glioma, and may serve as a novel therapeutic target and biomarker. The abnormal expressional loss of PAR5 in glioma tissues may contribute to tumor progression and the poor prognosis of patients with glioma.

There is evidence to show that IncRNAs regulate target expression through distinct mechanisms in different cancer cells. Using RIP and RNA pull-down analysis, we showed that PAR5 could bind directly to several RNA binding proteins, including EZH2, LSD1 and SUZ12, particularly EZH2. EZH2 is the core structural catalytic subunit of PRC2, which can silence target genes through induction of methylating lysine 27 of histone 3 (H3K27) and mediation of DNA methylation (42). EZH2 was identified as an RNA-binding component protein of PRC2 and may bind cooperatively to target RNAs (43). Moreover, EZH2 is pivotal to maintain the undifferentiated status of neuroblastoma by epigenetic repression of various tumor-suppressor genes (44). Reseach investigating the prognostic role of EZH2 in glioma patients, suggested that EZH2 may be applied as a potential biomarker for glioma (45-47). Recently, researchers have proposed that lncRNAs may interact with EZH2, thereby repressing target oncogene expression (48-50). To determine whether PAR5 regulates targets using a similar mechanism, we carried out western blotting to evaluate the relative expression of various oncogene-coding proteins involved in proliferation, tube formation and motility of glioma cells.

Cyclin A is a key molecular regulator of cell cycle progression from $\mathrm{S}$ to $\mathrm{G} 2$ phase by activating CDK2. This regulatory pathway is involved in cell proliferation and tube formation and is closely associated with tumor development and morbidity $(51,52)$. Glioma cells commonly share abnormalities in pathway signaling through the EGFR $(53,54)$ and its 
downstream phosphoinositide 3-kinase/protein kinase B (PI3K/ AKT) pathways (55). EGFR and VEGF-A are demonstrated to play key regulatory roles in tumor tube formation (56-58). Reports have revealed that EGFR overexpression in general carries worse prognosis (59). Furthermore, p-AKT and EGFR are well-known oncogenes that play essential roles in the control of glioma cell proliferation (60). The present data found that the expression levels of EGFR, VEGF-A, cyclin A and $\mathrm{p}-\mathrm{AKT}$ are downregulated after PAR5 restoration in glioma cells, suggesting that these genes are involved in the carcinogenic progression of glioma by PAR5-EZH2.

Given these findings, the present data indicated that PAR5 may elicit decreased proliferation and motility in glioma cells by interacting with EZH2 and altering expression levels of various oncogenes, including EGFR, VEGF-A, cyclin A, AKT and p-AKT. However, further high-throughput RNA sequencing, novel targets of PAR5 and correlation analysis in glioma cells are needed.

In conclusion, the present study revealed decreased PAR5 in glioma tissues of patients and glioma cells. The reduced PAR5 expression was correlated with clinicopathological features and the 5-year survival rate of glioma patients. Restoration of PAR5 expression by pcDNA3.1-PAR5 transfection inhibited the proliferation and motility of human glioma cells. RIP and RNA pull-down assay showed that PAR5 directly interacted with EZH2. Furthermore, restoration of PAR5 also suppressed expression levels of EFGR, VEGF-A, cyclin A and p-AKT in glioma cells. These data demonstrated that PAR5, as a tumor suppressor, reduced proliferation and motility of glioma cells by interacting with EZH2 and regulating oncogene expression. This finding may provide a therapeutic approach for the future treatment of glioma.

\section{Acknowledgements}

The present study was supported by a fund of the Applied Basic Research of Yunnan Province, joint special project of Kunming Medical University [grant no. 2017FE467 (-174)]; and Research institutes in Yunnan medical and health units project (grant no. 2017NS058).

\section{References}

1. Ricard D, Idbaih A, Ducray F, Lahutte M, Hoang-Xuan K and Delattre JY: Primary brain tumours in adults. Lancet 379: 1984-1996, 2012.

2. Louis DN, Ohgaki H, Wiestler OD, Cavenee WK, Burger PC, Jouvet A, Scheithauer BW and Kleihues P: The 2007 WHO classification of tumours of the central nervous system. Acta Neuropathol 114: 97-109, 2007.

3. van den Bent MJ: Interobserver variation of the histopathological diagnosis in clinical trials on glioma: A clinician's perspective. Acta Neuropathol 120: 297-304, 2010.

4. Joseph JV, Balasubramaniyan V, Walenkamp A and Kruyt FA: TGF- $\beta$ as a therapeutic target in high grade gliomas - promises and challenges. Biochem Pharmacol 85: 478-485, 2013.

5. Nicolaidis S: Biomarkers of glioblastoma multiforme. Metabolism 64 (Suppl 1): S22-S27, 2015.

6. Ponting CP, Oliver PL and Reik W: Evolution and functions of long non-coding RNAs. Cell 136: 629-641, 2009.

7. Caley DP, Pink RC, Trujillano D and Carter DR: Long noncoding RNAs, chromatin, and development. Sci World J 10: 90-102, 2010.

8. Wapinski $\mathrm{O}$ and Chang HY: Long non-coding RNAs and human disease. Trends Cell Biol 21: 354-361, 2011.
9. Nagano T and Fraser P: No-nonsense functions for long noncoding RNAs. Cell 145: 178-181, 2011.

10. Spizzo R, Almeida MI, Colombatti A and Calin GA: Long non-coding RNAs and cancer: A new frontier of translational research? Oncogene 31: 4577-4587, 2012.

11. Gibb EA, Brown CJ and Lam WL: The functional role of long non-coding RNA in human carcinomas. Mol Cancer 10: 38, 2011.

12. Lee JT: Epigenetic regulation by long non-coding RNAs. Science 338: 1435-1439, 2012.

13. Takayama K, Horie-Inoue K, Katayama S, Suzuki T, Tsutsumi S, Ikeda K, Urano T, Fujimura T, Takagi K, Takahashi S, et al: Androgen-responsive long noncoding RNA CTBPl-AS promotes prostate cancer. EMBO J 32: 1665-1680, 2013.

14. Yang X, Song JH, Cheng Y, Wu W, Bhagat T, Yu Y, Abraham JM, Ibrahim S, Ravich W, Roland BC, et al: Long non-coding RNA HNF1A-AS1 regulates proliferation and migration in oesophageal adenocarcinoma cells. Gut 63: 881-890, 2014.

15. Guo H, Wu L, Yang Q, Ye M and Zhu X: Functional linc- $P O U 3 F 3$ is overexpressed and contributes to tumorigenesis in glioma. Gene 554: 114-119, 2015.

16. Zhang X, Sun S, Pu JK, Tsang AC, Lee D, Man VO, Lui WM, Wong ST and Leung GK: Long non-coding RNA expression profiles predict clinical phenotypes in glioma. Neurobiol Dis 48: $1-8,2012$

17. Zhang XQ, Sun S, Lam KF, Kiang KM, Pu JK, Ho AS, Lui WM, Fung CF, Wong TS and Leung GK: A long non-coding RNA signature in glioblastoma multiforme predicts survival. Neurobiol Dis 58: 123-131, 2013.

18. Maleszewska M and Kaminska B: Deregulation of histonemodifying enzymes and chromatin structure modifiers contributes to glioma development. Future Oncol 11: 2587-2601, 2015.

19. Lee J, Solomon DA and Tihan T: The role of histone modifications and telomere alterations in the pathogenesis of diffuse gliomas in adults and children. J Neurooncol 132: 1-11, 2017.

20. Conway E, Healy E and Bracken AP: PRC2 mediated H3K27 methylations in cellular identity and cancer. Curr Opin Cell Biol 37: 42-48, 2015.

21. Wu J, Hu L, Du Y, Kong F and Pan Y: Prognostic role of LSD1 in various cancers: Evidence from a meta-analysis. Onco Targets Ther 8: 2565-2570, 2015.

22. Tsai MC, Manor O, Wan Y, Mosammaparast N, Wang JK, Lan F, Shi Y, Segal E and Chang HY: Long non-coding RNA as modular scaffold of histone modification complexes. Science 329: 689-693, 2010

23. Nie F, Yu X, Huang M, Wang Y, Ma H, Wang Z, De W and Sun M: Long noncoding RNA ZFAS1 promotes gastric cancer cells proliferation by epigenetically repressing KLF2 and NKD2 expression. Oncotarget 8: 38227-38238, 2017.

24. Li W, Sun M, Zang C, Ma P, He J, Zhang M, Huang Z, Ding Y and Shu Y: Upregulated long non-coding RNA AGAP2-AS1 represses LATS2 and KLF2 expression through interacting with EZH2 and LSD1 in non-small-cell lung cancer cells. Cell Death Dis 7: e2225, 2016.

25. Louis DN, Perry A, Reifenberger G, von Deimling A, FigarellaBranger D, Cavenee WK, Ohgaki H, Wiestler OD, Kleihues P and Ellison DW: The 2016 World Health Organization Classification of Tumors of the Central Nervous System: a summary. Acta Neuropathol 131: 803-820, 2016. doi: 10.1007/s00401-016-1545-1

26. Louis DN, Ohgaki H, Wiestler OD, Cavenee WK, Burger PC, Jouvet A, Scheithauer BW and Kleihues P: The 2007 WHO Classification of Tumours of the Central Nervous System. Acta Neuropathol 114: 97-109, 2007. doi: 10.1007/s00401-007-0243-4.

27. Song S, Fajol A, Tu X, Ren B and Shi S: miR-204 suppresses the development and progression of human glioblastoma by targeting ATF2. Oncotarget 7: 70058-70065, 2016.

28. Arita H, Narita Y, Matsushita Y, Fukushima S, Yoshida A, Takami H, Miyakita Y, Ohno M, Shibui S and Ichimura K: Development of a robust and sensitive pyrosequencing assay for the detection of $I D H 1 / 2$ mutations in gliomas. Brain Tumor Pathol 32: 22-30, 2015.

29. Arita H, Narita Y, Fukushima S, Tateishi K, Matsushita Y, Yoshida A, Miyakita Y, Ohno M, Collins VP, Kawahara N, et al: Upregulating mutations in the TERT promoter commonly occur in adult malignant gliomas and are strongly associated with total 1p19q loss. Acta Neuropathol 126: 267-276, 2013.

30. Mulholland S, Pearson DM, Hamoudi RA, Malley DS, Smith CM, Weaver JM, Jones DT, Kocialkowski S, Bäcklund LM, Collins VP, et al: $M G M T$ CpG island is invariably methylated in adult astrocytic and oligodendroglial tumors with $I D H 1$ or $I D H 2$ mutations. Int J Cancer 131: 1104-1113, 2012. 
31. Okita Y, Narita Y, Miyakita Y, Ohno M, Matsushita Y, Fukushima S, Sumi M, Ichimura K, Kayama T and Shibui S: $I D H 1 / 2$ mutation is a prognostic marker for survival and predicts response to chemotherapy for grade II gliomas concomitantly treated with radiation therapy. Int J Oncol 41: 1325-1336, 2012.

32. Zhang Q, Matsuura K, Kleiner DE, Zamboni F, Alter HJ and Farci P: Analysis of long non-coding RNA expression in hepatocellular carcinoma of different viral etiology. J Transl Med 14: 328, 2016.

33. Chen ZH, Hu HK, Zhang CR, Lu CY, Bao Y, Cai Z, Zou YX, $\mathrm{Hu} \mathrm{GH}$ and Jiang L: Down-regulation of long non-coding RNA FOXD3 antisense RNA 1 (FOXD3-AS1) inhibits cell proliferation, migration, and invasion in malignant glioma cells. Am J Transl Res 8: 4106-4119, 2016.

34. Liang L, Wong CM, Ying Q, Fan DN, Huang S, Ding J, Yao J, Yan M, Li J, Yao M, et al: MicroRNA-125b suppressesed human liver cancer cell proliferation and metastasis by directly targeting oncogene LIN28B2. Hepatology 52: 1731-1740, 2010.

35. He Z, Huang C, Lin G and Ye Y: siRNA-induced TRAF6 knockdown promotes the apoptosis and inhibits the invasion of human lung cancer SPC-A1 cells. Oncol Rep 35: 1933-1940, 2016.

36. Turkalp Z, Karamchandani J and Das S: $I D H$ mutation in glioma: New insights and promises for the future. JAMA Neurol 71: 1319-1325, 2014

37. Yan H, Parsons DW, Jin G, McLendon R, Rasheed BA, Yuan W, Kos I, Batinic-Haberle I, Jones S, Riggins GJ, et al: IDH1 and IDH2 mutations in gliomas. N Engl J Med 360: 765-773, 2009.

38. Zhang YA, Ma X, Sathe A, Fujimoto J, Wistuba I, Lam S, Yatabe Y, Wang YW, Stastny V, Gao B, et al: Validation of SCT methylation as a hallmark biomarker for lung cancers. J Thorac Oncol 11: 346-360, 2016.

39. Malmström A, Grønberg BH, Marosi C, Stupp R, Frappaz D, Schultz H, Abacioglu U, Tavelin B, Lhermitte B, Hegi ME, et al; Nordic Clinical Brain Tumour Study Group (NCBTSG): Temozolomide versus standard 6-week radiotherapy versus hypofractionated radiotherapy in patients older than 60 years with glioblastoma: The Nordic randomised, phase 3 trial. Lancet Oncol 13: 916-926, 2012.

40. Wick W, Platten M, Meisner C, Felsberg J, Tabatabai G, Simon M, Nikkhah G, Papsdorf K, Steinbach JP, Sabel M, et al; NOA-08 Study Group of Neuro-oncology Working Group (NOA) of German Cancer Society: Temozolomide chemotherapy alone versus radiotherapy alone for malignant astrocytoma in the elderly: The NOA-08 randomised, phase 3 trial. Lancet Oncol 13: 707-715, 2012

41. Arita H, Yamasaki K, Matsushita Y, Nakamura T, Shimokawa A, Takami H, Tanaka S, Mukasa A, Shirahata M, Shimizu S, et al: A combination of TERT promoter mutation and MGMT methylation status predicts clinically relevant subgroups of newly diagnosed glioblastomas. Acta Neuropathol Commun 4: 79, 2016.

42. Chinaranagari S, Sharma P and Chaudhary J: EZH2 dependent $\mathrm{H} 3 \mathrm{~K} 27 \mathrm{me} 3$ is involved in epigenetic silencing of ID4 in prostate cancer. Oncotarget 5: 7172-7182, 2014.

43. Betancur JG and Tomari Y: Cryptic RNA-binding by PRC2 components EZH2 and SUZ12. RNA Biol 12: 959-965, 2015.

44. Wang C, Liu Z, Woo CW, Li Z, Wang L, Wei JS, Marquez VE, Bates SE, Jin Q, Khan J, et al: EZH2 mediates epigenetic silencing of neuroblastoma suppressor genes $C A S Z 1, C L U, R U N X 3$, and NGFR. Cancer Res 72: 315-324, 2012.
45. Wu Z, Wang Q, Wang L, Li G, Liu H, Fan F, Li Z, Li Y and Tu Y: Combined aberrant expression of Bmil and EZH2 is predictive of poor prognosis in glioma patients. J Neurol Sci 335: 191-196, 2013.

46. Zhang J, Chen L, Han L, Shi Z, Zhang J, Pu P and Kang C: EZH2 is a negative prognostic factor and exhibits pro-oncogenic activity in glioblastoma. Cancer Lett 356: 929-936, 2015.

47. Zhang Y, Yu X, Chen L, Zhang Z and Feng S: EZH2 overexpression is associated with poor prognosis in patients with glioma. Oncotarget 8: 565-573, 2017.

48. Huang M, Hou J, Wang Y, Xie M, Wei C, Nie F, Wang Z and Sun M: Long noncoding RNA LINC00673 is activated by SP1 and exerts oncogenic properties by interacting with LSD1 and EZH2 in gastric cancer. Mol Ther 25: 1014-1026, 2017.

49. Sun CC, Li SJ, Li G, Hua RX, Zhou XH and Li DJ: Long intergenic non-coding RNA 00511 acts as an oncogene in nonsmall-cell lung cancer by binding to EZH2 and suppressing p57. Mol Ther Nucleic Acids 5: e385, 2016.

50. Ding J, Xie M, Lian Y, Zhu Y, Peng P, Wang J, Wang L, Wang K: Long non-coding RNA HOXA-AS2 represses P21 and KLF2 expression transcription by binding with EZH2, LSD1 in colorectal cancer. Oncogenesis 6: e288, 2017.

51. Du WW, Yang W, Liu E, Yang Z, Dhaliwal P and Yang BB: Foxo3 circular RNA retards cell cycle progression via forming ternary complexes with p21 and CDK2. Nucleic Acids Res 44: 2846-2858, 2016.

52. Liu F, Tong D, Li H, Liu M, Li J, Wang Z and Cheng X: Bufalin enhances antitumor effect of paclitaxel on cervical tumorigenesis via inhibiting the integrin $\alpha 2 / \beta 5 / F A K$ signaling pathway. Oncotarget 7: 8896-8907, 2016.

53. Ivkovic S, Canoll $\mathrm{P}$ and Goldman JE: Constitutive EGFR signaling in oligodendrocyte progenitors leads to diffuse hyperplasia in postnatal white matter. J Neurosci 28: 914-922, 2008.

54. Galvez-Contreras AY, Quiñones-Hinojosa A and Gonzalez-Perez O: The role of EGFR and ErbB family related proteins in the oligodendrocyte specification in germinal niches of the adult mammalian brain. Front Cell Neurosci 7: 258, 2013.

55. Huse JT and Holland EC: Targeting brain cancer: Advances in the molecular pathology of malignant glioma and medulloblastoma. Nat Rev Cancer 10: 319-331, 2010.

56. Zhu Y, Zhang X, Qi L, Cai Y, Yang P, Xuan G and Jiang Y: HULC long non-coding RNA silencing suppresses angiogenesis by regulating ESM-1 via the PI3K/Akt/mTOR signaling pathway in human gliomas. Oncotarget 7: 14429-14440, 2016.

57. Wang Q, Cheng F, Ma TT, Xiong HY, Li ZW, Xie CL, Liu CY and Tu ZG: Interleukin-12 inhibits the hepatocellular carcinoma growth by inducing macrophage polarization to the M1-like phenotype through downregulation of Stat-3. Mol Cell Biochem 415: 157-168, 2016.

58. Sun L, Zhang Q, Li Y, Tang N and Qiu X: CCL21/CCR7 up-regulate vascular endothelial growth factor-D expression via ERK pathway in human non-small cell lung cancer cells. Int J Clin Exp Pathol 8: 15729-15738, 2015.

59. Jansen M, Yip S and Louis DN: Molecular pathology in adult gliomas: Diagnostic, prognostic, and predictive markers. Lancet Neurol 9: 717-726, 2010.

60. Yang P, Qiu Z, Jiang Y, Dong L, Yang W, Gu C, Li G and Zhu Y: Silencing of cZNF292 circular RNA suppresses human glioma tube formation via the Wnt/ $\beta$-catenin signaling pathway. Oncotarget 7: 63449-63455, 2016. 